\title{
A Study to Assess the Family Burden and Coping Strategies among the Caregivers of Patients with Schizophrenia \\ *Prof. A. Rajathi\&**Dr. Gandhimathi
}

\begin{abstract}
Schizophrenia has often been described as the "cancer" of mental illness and care giving is a burdensome task for the family members. Assessing the family burden and coping strategies among the caregivers of patients with schizophrenia may help the caregivers to understand the nature of the problem and plan for better care. The Non experimental descriptive design was used. Fifty caregivers of schizophrenic patients were selected by using Non probability purposive sampling technique. Semi structured interview schedule and Coping inventory was used to assess the level of family burden \& coping strategies of the caregivers of schizophrenic patients. The results regarding the Family burden of caregivers shows that 24(48\%) of them had no burden and only 13(26\%) of them had severe burden in the item of loss of patients income. $38(76 \%)$ of them had no burden and $6(12 \%)$ of them had severe burden in the item of family become secluded or withdrawn from others. Regarding coping strategies of caregivers in problem oriented coping method $74 \%$ of the them "Always ${ }^{\text {ee }}$ used the item of „Accept the situation as it is ${ }^{\text {ee }}$ and Inaffective oriented coping strategies $82 \%$ of them ,Always ${ }^{\text {ee }}$ used the item of ,praye as a coping method. The study concludes that the caregivers of schizophrenic patients experience burden on the physical, emotional, financial aspects and the extent of the burden is closely linked to the amount of symptomatic behaviour of the patient. Coping positively will not only make the caregivers to feel better and also they will be able to take better care of schizophrenicpatients.
\end{abstract}

\section{Introduction}

To keep the body in good health is a duty...otherwise we shall not be able to keep ourmind strong and clear

\section{-Buddha}

Schizophrenia has often been described as the "cancer" of mental illness. The word schizophrenia was coined in 1908 by the Swiss psychiatrist Eugen Bleuler. It was derived from the Greek words "Skhizo" means split and "Phren" means mind. Schizophrenia is defined as a severe mental condition in which there is disorganization of the personality, disorientation in social functioning,andlossofcontactwith,or distortion of reality. There may be evidences of hallucinations and delusional thinking.

An estimated $50 \%$ to $80 \%$ of persons with schizophrenia and related psychotic disorders live with or have regular contact with a family caregiver. Caring for someone with mental health problems can be challenging and difficult responsibility. The burden of caring for a mentally ill individual often falls on the patient ee $^{\text {immediate family }}$ or relatives. While caring for someone else can be very rewarding, it can also be a stressful and demanding one, taking its toll both emotionally and physically on the caregiver.

Demands of care giving includes managing the activity of daily living of 
patient by caregivers, paying for psychiatric treatment, supervision of a mentally ill family member, dealing with societal stigma associated with mental illness, and emotional distress that may result from symptoms of a family member'es illness.

As a result of the high proportion of family members providing care to persons with schizophrenia and the high rates of burden reported by these caregivers, researcher have attempted to identify predictors of family burden and their coping level of care givers with schizophrenia and also the strategies by which caregiver can be helped.

\section{Objectives}

1. To assess the level of family burden among the caregivers of the schizophrenicpatients.

2. To assess the coping strategies adopted by the caregivers of the schizophrenicpatients

3. To correlate the family burden with coping strategies adopted among the caregivers ofthe schizophrenicpatients.

4. To associate the family burden and coping strategies with selected demographic variables

\section{Methodology}

The descriptive design based on the quantitative approach was adopted. The study was conducted at ATHMA hospital at Trichy. The population consisted of care givers of psychotic patients. The sample consisted of 50 caregivers of schizophrenic patients .The study was conducted over a period of six weeks using Non probability purposive sampling technique. The researcher explained the purpose of the study and written consent was obtained from the samples. The patient andparticipants were first registered in the outpatient department and then to the psychiatrist. Then the participants were taken to thecounseling room and the interview was conducted by theresearcher.

\section{Inclusion criteria:}

1. Care givers who were 18 years orabove

2. The care giver who stayed with the patient and provided minimum one year of care to thePatients.

3. Both male and femalecaregivers

\section{Exclusion criteria}

1. Care givers of psychotic patients who do not know English orTamil

2. Care givers who do not give consent for thestudy.

3. The care givers who were having any obvious psychiatricillness.

\section{Description of the tool}

1. The Demographic variables of the Schizophrenic Patient ${ }^{\text {ee }}$ Caregivers

2. The Demographic variables of the SchizophrenicPatients

3. Semi structured interview schedule to assess the family burden of caregivers (SAFB, Pai and Kapur,1981)

4. Coping inventory to assess the coping level of caregivers with schizophrenic patients (Lazarus, 2001, Moran2001)

\section{Ethical consideration}

Formal permission was obtained from Head of Department of ATHMA hospital.

Informed consent was obtained from the study participants. Assurance was given to the participants regarding the confidentiality of collected data 


\section{Findings}

Table I: Frequency distribution of Burden of caregiver of patients with schizophrenia

\begin{tabular}{|l|l|l|l|l|l|l|l|l|}
\hline S.No & Items & \multicolumn{2}{l}{ No Burden } & \multicolumn{2}{l|}{$\begin{array}{l}\text { Moderate } \\
\text { Burden }\end{array}$} \\
\cline { 3 - 9 } & & No & $\%$ & No & $\%$ & No & $\%$ \\
\hline 1 & Loss of patient Income & 24 & 48 & 13 & 26 & 13 & 26 \\
\hline 2 & $\begin{array}{l}\text { Expense due to patient illness or } \\
\text { treatment }\end{array}$ & 15 & 30 & 17 & 34 & 18 & 36 \\
\hline 3 & $\begin{array}{l}\text { Patient not helping in the house hold } \\
\text { work }\end{array}$ & 12 & 24 & 16 & 32 & 22 & 44 \\
\hline 4 & Family become secluded or withdrawn & 38 & 76 & 6 & 12 & 6 & 12 \\
\hline 5 & $\begin{array}{l}\text { Any members of the family become } \\
\text { depressed, weepy orirritable }\end{array}$ & 11 & 22 & 21 & 42 & 18 & 36 \\
\hline
\end{tabular}

Table I shows that $24(48 \%)$ had no burden and $13(26 \%)$ of them had severe burden in the item of loss of patients income. 18 (36\%) had severe burden and $15(30 \%)$ of them had no burden due to expenditure of the family members for the patients treatment. 22 (44\%) had severe burden and $12(24 \%)$ of them had no burden in theitem of patient inability to help in the house hold work. $38(76 \%)$ had no burden and six $(12 \%)$ of them had severe burden in the item of family become secluded or withdrawn from others. $11(22 \%)$ were able to cope normally and $21(42 \%)$ of them become depressed, weepy orirritable. 


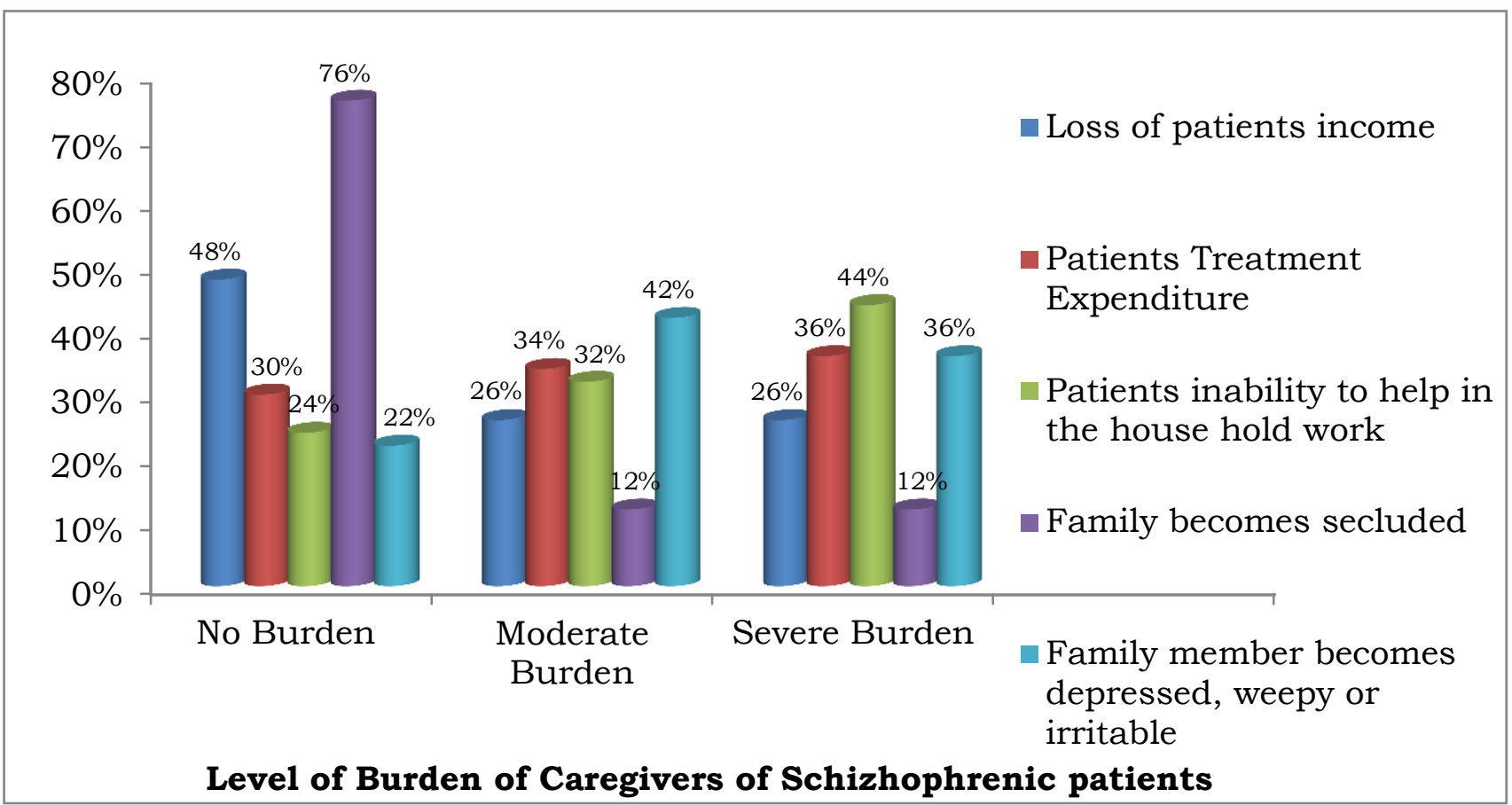

Table II: Frequency distribution of coping strategies of caregivers of patients with schizophrenia

\begin{tabular}{|l|l|l|l|l|l|l|l|}
\hline S.No & Items & \multicolumn{2}{l|}{ Never } & \multicolumn{2}{l|}{ Sometimes } & \multicolumn{2}{l|}{ Always } \\
\cline { 3 - 9 } & & No & $\%$ & No & $\%$ & No & $\%$ \\
\hline 1 & $\begin{array}{l}\text { Problem oriented methods } \\
\text { Maintain Control over the situation }\end{array}$ & 2 & 4 & 19 & 38 & 29 & 58 \\
\hline 2 & Accept the situation as it is & 2 & 4 & 11 & 22 & 37 & 74 \\
\hline 3 & $\begin{array}{l}\text { Breaking the problem into smaller } \\
\text { pieces }\end{array}$ & 4 & 8 & 22 & 44 & 24 & 48 \\
\hline 4 & $\begin{array}{l}\text { Affective Oriented methods } \\
\text { Hope }\end{array}$ & 4 & 8 & 14 & 28 & 32 & 64 \\
\hline 5 & Pray & 2 & 4 & 7 & 14 & 41 & 82 \\
\hline 6 & Cry, get depressed & 10 & 20 & 30 & 60 & 10 & 20 \\
\hline
\end{tabular}


Table II shows the coping strategies adopted by caregivers of schizophrenic patients in the problem oriented coping strategy shows that twenty nine care givers $(58 \%)$,,always ${ }^{\text {ee }}$ used the item of ,Maintain control over the situation "e. Majority of the care givers (74\%), always ${ }^{\text {ee }}$ used the item of „Acceptthesituationasitis ${ }^{\text {ee }}$. Twentytwo care givers(44\%) ,sometimes ${ }^{c e}$ used the item of „breaking downthe problem into small pieces $^{\text {ee }}$ $24(48 \%)$ of them ,always ${ }^{\text {ee }}$ used it.In affective oriented coping strategies, thirty two care givers (64\%) ,alwayse used „hope ${ }^{\text {ee }}$ as a coping method. Majority

\section{Recommendations}

\section{- A comparative study on male family} members and female members can be carriedout.

- A same study can be conducted in the community setup.

\section{- A comparative study with particular age} group of the patients and their caregiveres burden and coping can beassessed.

- A comparative study with duration of illness of the patients and their caregiverees burden and coping can beassessed.
With regards to association between demographic variables and burden of caregivers, there was a significant association between caregiver"s marital status ( $p$ value $<0.05$ ) with the burden of caregivers. The other variables like age, sex, religion, residence, education, occupation, income, and duration of the illness had no burden of the care givers.

$$
\text { regards }
$$

ssociation

between demographic variables and coping of caregivers, there is a significant

association between sex and residence ofthe

of them (82\%) ,always "e used the itemof ,prayee. Thirty care givers (60\%) „,sometimesee used the item of ,cry and get depressed as a coping method in solving theirproblems.

There is a significant association between coping strategies in the items of hope, accepting the situation as it is, breaking the problems into smaller pieces and talking over the problem with someone else with the burden perceived by the caregivers of schizophrenia $(\mathrm{P}>0.05)$. The other items like pray, try to put the problem out of your mind, sleep, physical activity, past experience and maintain control over the situation had no association with burden of thecaregivers. caregivers ( $\mathrm{p}$ value $<0.05$ ) with coping strategies used by them. The other variables like age, religion, residence, occupation of the caregivers did not show any significant relationship with the coping strategies used by the caregivers.

\section{Conclusion}

Caregivers of schizophrenic patients experience burden on the physical, emotional, financial aspects and the extent of the burden is closely linked to the amount of symptomatic behaviour of the patient. Coping positively will not only make the caregivers to feel better and also they will be able to take better care of schizophrenic patients. 


\section{References}

1. Barroso,Bandeira and Nascimento (2009), Predictors of subjective burden for families of psychiatric patients treated in the public health care system in Belo Horizonte, Canrnos de SaudePublica. 25(9),1957-68

2. Biegel, Milligan, Putnamand Song (1994), Predictors of burden among lower socioeconomic status caregivers of persons with chronic mental illness, Journal of Family Social Work. 13(2),25-44.

3. Breitborde,Lopez,Chang, Kopelowicz and Zarate (2009), Emotional over-involvement can be deleterious for caregivers' health: Mexican Americans caring for a relative with schizophrenia, Social Psychiatry and Psychiatric Epidemiology. 44(9), 716-23.

4. Caqueo-Urízar, Gutierrez-Maldonado, Ferrer-Garcia, Darrigrande-Molina (2011), Burden of care in Aymara caregivers of patients with schizophrenia, Acquired Immune Deficiency Syndrome. 1;58(4), 42932

5. Caqueo-Urizar, Gutierrez-Maldonado, Ferrer-Garcia, Penaloza-Salazar, RichardsAraya and Cuadra-Peralta (2011), Attitudes and burden in relatives of patientswith schizophrenia in a middle income country, BMC Family Practice. 2011, 12:101

6. Chadda, Singh and Ganguly (2007), Caregiver burden and coping: a prospective study of relationship between burden and coping in caregivers of patients with schizophrenia and bipolar affective disorder, Social Psychiatry and Psychiatric Epidemiology.42(11):923-30.

7. Cherkil (2010), Coping styles, stress tolerance, and wellbeing and their correlations in the women spouses of the mentally ill, Indian Journal of Psychological Medecine.32:99-103

8. Chien, Chan and Morrissey (2007), The perceived burden among Chinese family caregivers of people with schizophrenia, Journal of Clinical Nursing.16(6):1151-61

9. Grover, et al. (2012), Comparative study of the experience of caregiving in bipolar affective disorder and schizophrenia. International Journal Social Psychiatry. 58(6):614-22.

10. Boyd A Mary. (2008), Psychiatric Nursing Contemporary Practice, Lippincot. 35-34 